\title{
Behind the Eastern-Western European convergence path: the role of geography and trade liberalization
}

\author{
Adolfo Cristobal-Campoamor • \\ Osiris Jorge Parcero
}

Received: 20 June 2011 / Accepted: 15 March 2013 / Published online: 2 April 2013

(C) Springer-Verlag Berlin Heidelberg 2013

\begin{abstract}
This paper proposes a 2-block 3-region economic geography model that can account for the most salient stylized facts experienced by Eastern European transition economies during the period 1990-2005. In contrast to the existing literature, which has favored technological explanations, trade liberalization is the only driving force. The model correctly predicts that in the first half of the period, trade liberalization led to divergence in GDP per capita, both between the West and the East and within the East. Consistent with the data, in the second half of the period, this process was reversed and convergence became the dominant force.
\end{abstract}

\section{JEL Classification $\mathrm{F} 12 \cdot \mathrm{F} 15 \cdot \mathrm{P} 2$}

\section{Introduction}

From the beginning of the 1990s to 2005, the Eastern European economic transition has been characterized by a U-shaped pattern of relative development (see Fig. 1). Initially, relative income per capita between Eastern and Western Europe diverged, but roughly from 1999 onwards, this pattern was reversed and Eastern Europe started to catch up with its Western counterpart. Moreover, when analyzing the performance inside Eastern Europe, a similar pattern emerges. The countries closer to the West

\footnotetext{
A. Cristobal-Campoamor $(\varangle)$

Graduate School of Economics and Management, Ural Federal University,

Yekaterinburg, Russia

e-mail: adolfocristobal@gmail.com

O. J. Parcero

Department of Economics and Finance, College of Business and Economics,

United Arab Emirates University, Al Ain, United Arab Emirates

e-mail: osirisjorge.parcero@gmail.com
} 


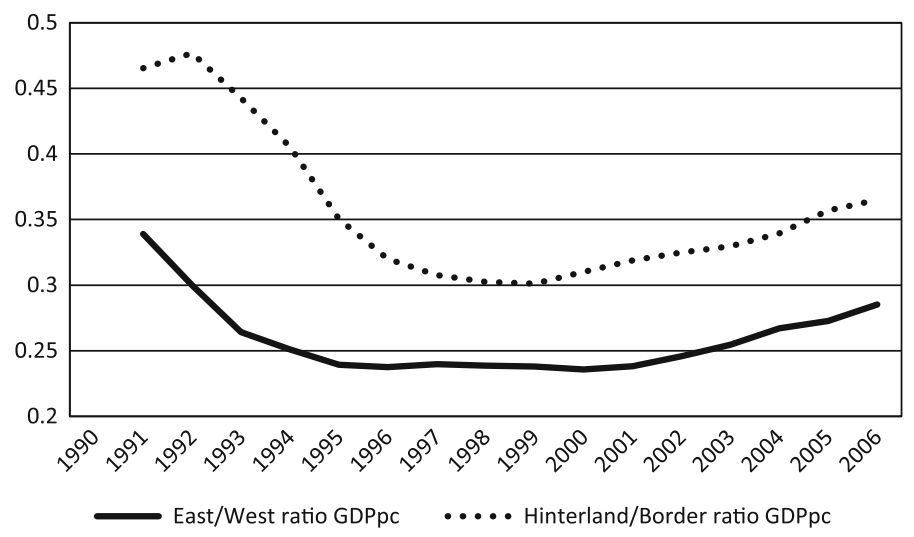

Fig. 1 East/West and Hinterland/Border GDP per capita ratios

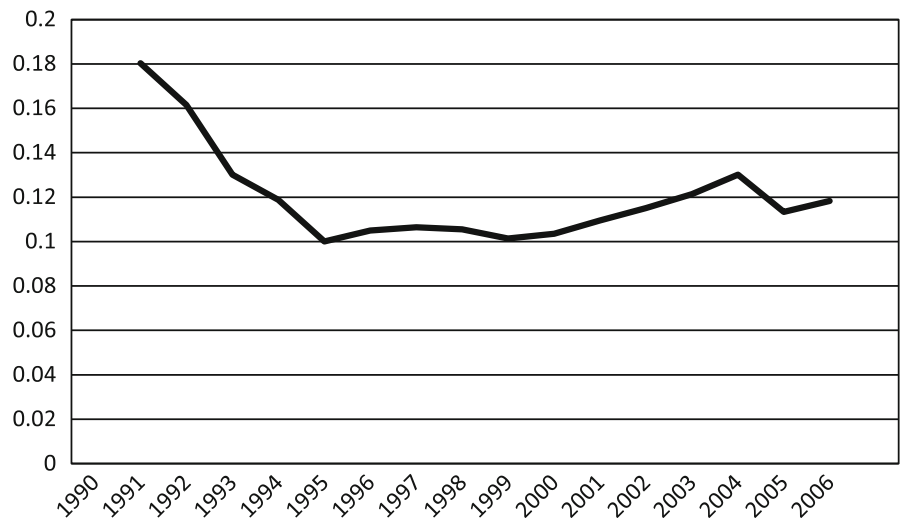

Fig. 2 East/West industrial output ratio

(Border) initially experienced faster growth than those situated further from the West (Hinterland), but from the end of the 1990s, this was also reversed.

A similar pattern can be observed when the attention is focused on industrial output. Hinterland (East) initially suffered a continuous relative deindustrialization, followed by a remarkable recovery from the beginning of the new century (see Figs. 2 and 3). Thus, the stylized facts exhibit both an East-West and a Border-Hinterland U-shaped pattern in terms of (real) GDP per capita and industrial output.

The literature has typically explained these U-shaped patterns by relying on technological arguments or on the misallocation of factors of production. Boldrin and Canova (2003), for example, suggest that the technological obsolescence led to an initial period of intense unemployment and reallocations after trade was liberalized. Blanchard (1996) and Blanchard and Kremer (1997) link the initial slump to microeconomic "disorganization": the collapse of the state sector was precipitated by traditional input suppliers, who found attractive opportunities outside the state sector and broke the established productive chains. Cociuba (2006) and Keller (1997) also stress the role played by technology adoption to account for the GDP trajectories of Eastern 


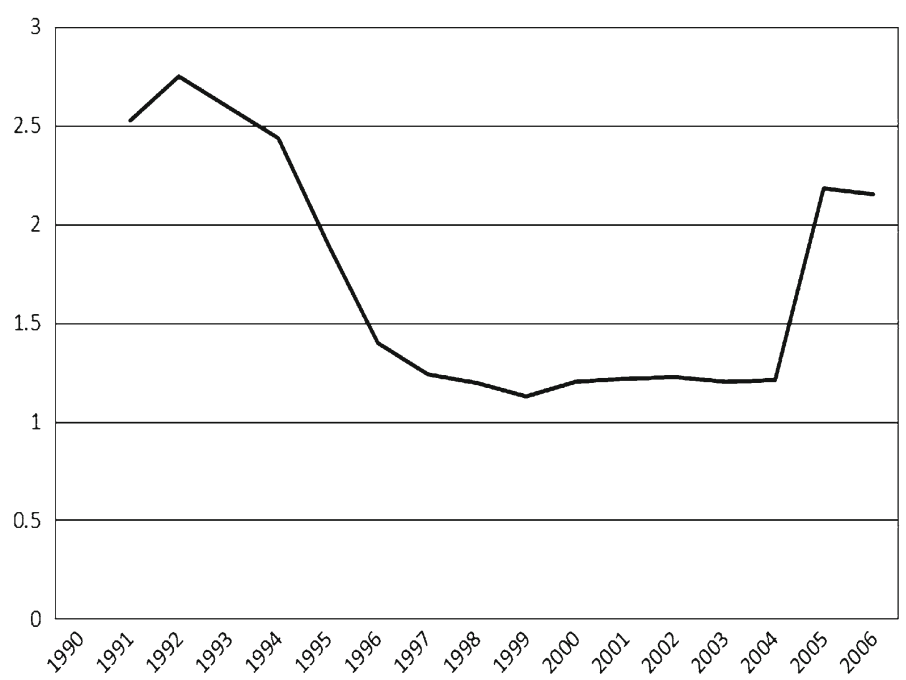

Fig. 3 Hinterland/Border industrial output ratio

European countries. The existing literature thus puts the emphasis on the intensity of reallocations that were needed to adapt to a superior Western technology, followed by a remarkable catch-up process that was conditioned by redistributive public policies.

While we do not claim these explanations are erroneous in any way, in this paper, we deliberately disregard issues of technological backwardness or sectorial misallocations. Instead, we propose an economic geography model where trade liberalization is the only driving force. This is based on our belief that the trade reorientation toward the West and the initial deterioration of the market for exports were crucial initial conditions for the transition (see, among others, Campos and Coricelli 2002; Christoffersen and Doyle 1998; De Melo et al. 2001 or Tondl and Vuksic 2003). Our focus is on the evolution of the Eastern European economies right after the collapse of the socialist experiment. Besides, we hope the insights derived from our experiment could be relevant to analyze other trade liberalization processes in different countries. Since it can be argued that, prior to the transition period, all Central and Eastern European countries shared similar technological and institutional conditions; we claim that the disparate evolutions of Border and Hinterland may have something to do with the relative proximity to the EU market. That is the reason why we emphasize the causal determinants related to geography and trade openness.

We develop a model with 2 blocks (West and East) and three regions (one region in the West, and a Border and Hinterland in the East). As is usually the case in the Economic Geography literature, our model assumes that agriculture is perfectly competitive, industry is monopolistically competitive and workers are perfectly mobile between sectors. Trade in industrial goods is subject to transport costs, which are higher between Hinterland and West than between Border and West. As in Krugman and Venables (1995) and Puga (1999), industrial firms use intermediate goods, which gives rise to forward and backward linkages. The relative size of the endowments of 
labor and land in our model match the actual shares in our three regions. For simplicity and to make our results as sharp as possible, we assume that West and East exhibit identical technologies.

This simple setup, which abstracts from technological differences, is sufficient to account for the main stylized facts. The focus of our analysis is the pattern of convergence in terms of GDP and industrialization (between East and West; Hinterland and Border) produced by the trade liberalization during the transition period. Our model can be viewed as a generalization of Krugman and Venables (1995) and Puga (1999). They showed how in a two-block model the earlier stages of trade liberalization could bring about lower real wages and deindustrialization in disfavored markets.

Our paper differentiates from Puga (1999) in that we allow for internal trade costs within the East, making the setup non-equidistant. In that way, Border and Hinterland become asymmetric in terms of their distance to the West. For that reason, we must rely on numerical simulations. This modification is not substantial from a purely theoretical point of view and so our paper should be considered only an empirical application of Puga (1999), with a slight structural modification. A similar exercise was undertaken by Bosker et al. (2010), with the qualification that they did not focus on the historical experience of transition, but they tried to shed light on the future impact (and only within the West) of the recent EU enlargement. Our paper is a contribution to this literature.

Our simulation results explain very well the actual relative evolution of the different regions described above. First, during the time following the trade liberalization, these results are as follows. Trade liberalization should initially lead to divergence in GDP per capita, both between West and East and between Border and Hinterland. The good performance of the West can be explained by a Home Market effect. As trade costs drop, the relative profitability varies in favor of the largest market. This same phenomenon leads to the relative initial deindustrialization of the East in favor of the West. Furthermore, the results show that there should be an initial divergence between Border and Hinterland in favor of the former location. This is the case because the proximity to the West involves a crucial access to the bulk of consumption goods and intermediate inputs.

Second, the results show that during the final stages of East-West trade liberalization, a convergence in GDP per capita should appear, both between Border and Hinterland and between East and West. On the one hand, this is the case because when international trade costs are sufficiently low, proximity to large markets is no longer a basic determinant of firms' location. On the other hand, the previous agglomeration in the West led to (relatively) lower wages in the Border and even more so in the Hinterland. This is now crucial for the recovery of a substantial manufacturing basis by the Border and to a larger extent by the Hinterland.

We also present a series of industry-level stylized facts to give additional support to our hypothesis that NEG forces were at work during the aforementioned regional convergence pattern. When we break down our output data by industry, we observe, as trade freeness increases, that sectors with significant scale economies and/or high value-to-weight ratios follow an inverted U-shape pattern in their geographical output concentration. The spatial concentration patterns of these sectors are strongly affected by economic geography forces, i.e., increasing returns to scale and transport costs. 
In contrast, sectors where scale economies are less relevant and value-to-weight ratios are lower follow a monotonic concentration pattern. The latter is more consistent with theories of comparative advantage. We argue that these stylized facts seem to be more consistent with a NEG approach and less so with the conventional technologicalobsolescence plus catch-up approach.

The paper is organized as follows. Section 2 mentions some additional related literature. Section 3 defines the three regions and further describes the main policy changes, justifying the adoption of the assumptions underlying our policy experiment. Section 4 briefly describes the stylized facts we aim to reproduce. Our modeling framework is introduced in Sect. 5, though it will be more extensively presented in the "Appendix"; we also discuss in Sect. 5 our numerical experiments studying the effects of trade liberalization. Section 6 shows some microeconomic stylized facts. Section 7 concludes.

\section{Other related literature}

In addition to the papers cited in the introduction, the following literature is worth mentioning. Some other papers have already developed more-than-two-region models of economic geography, either using the Dixit and Stiglitz's modeling framework (Krugman and Livas-Elizondo 1996; Alonso-Villar 1999; Monfort and Nicolini 2000; Crozet and Koenig-Soubeyran 2004 etc.) or using the Otaviano-Tabuchi-Thisse's one (Behrens et al. 2006). Ago et al. (2006) uses both methods and compares them in the context of a three-region model.

Another important paper is Venables (2000), who uses a three-location framework as well, but focuses on the internal geography of a developing country that is hardly industrialized for intermediate levels of trade costs. Venables' insights are probably more applicable to countries like China and India, which_-given their lower initial level of development-could not possibly experience divergence with respect to the West during their transition process. Our starting point is different because for all levels of trade costs, both West and East are significantly industrialized.

Nevertheless, to the best of our knowledge, only Forslid et al. (2002), Brulhart et al. (2004), Crozet and Koenig-Soubeyran (2004) and Iranzo and Peri (2009) were directly motivated by the experience of transition economies. Both Brulhart et al. (2004) and Forslid et al. (2002) present scenarios for the future economic geography of Europe, but without a retrospective approximation to the 1990s. In particular, Brulhart et al. (2004) pay attention to the internal geography of the West as a result of the EU enlargement. In contrast to their paper, our priority is to explore the patterns of industrial relocation within the East, together with their implications for relative (real) GDP per capita, during the period 1990-2005.

In the case of Crozet and Koenig-Soubeyran (2004), the authors also focus on the connections between external trade and internal geography, showing that both the concentration and the dispersion of industry are theoretically possible for Eastern Europe. These authors link the mass of manufacturing varieties to the (fixed) national stock of mobile labor (as in Krugman 1991). For this reason, they do not study the processes of industrialization/deindustrialization at the national level or reproduce our non-monotonic patterns of convergence. 
Finally, Iranzo and Peri (2009) examine the welfare consequences of the liberalization of both trade and East-West migration, with the first reform predating the second. For them, trade liberalization is a one-shot event instead of a gradual process. This implies that the non-monotonic patterns of convergence generated by trade openness cannot be captured by their model. Our model tries to fill this gap.

\section{Introducing the scenario under analysis}

\subsection{Definition of the three regions}

The different U-shapes mentioned in the introduction are robust to different criteria in the selection of Border and Hinterland countries. For instance, we could place in the Border those countries sharing boundaries with an EU-15 thriving economy. Alternatively, we could just call Border to the set of countries that joined (or will join soon, like Croatia) the European Union. ${ }^{1}$ Therefore, and without big loss of generality, we decided to choose the latter convention and specify our regions as follows: West (EU15), Border (Bulgaria, Croatia, Czech Republic, Estonia, Hungary, Latvia, Lithuania, Poland, Romania, Slovak Republic and Slovenia) and Hinterland (Albania, Armenia, Azerbaijan, Belarus, Georgia, Kazakhstan, Kyrgyz Republic, Macedonia, Moldova, Russian Federation, Tajikistan, Turkmenistan, Ukraine and Uzbekistan). ${ }^{2}$

Our choice of the national and supra-national (instead of the sub-national) levels as the relevant spatial dimensions to characterize our stylized facts has been deliberate. In that respect, we are consistent with the empirical literature, which emphasizes how in Eastern Europe country-specific factors are more important determinants of regional income differences than localized conditions (see Brulhart and Koenig-Soubeyran 2006; Melchior 2008 or Bosker 2009).

\subsection{Policy changes}

\subsubsection{West-Border trade liberalization}

The route toward East-West trade liberalization started quite early in some Eastern European countries like the former Yugoslavia and Romania. In particular, the European Community signed an initial Generalized System of Preferences with Romania in 1974, and an agreement on manufacturing trade was reached in 1980. Nevertheless, the most comprehensive Generalized Systems of Preferences (GSP) were approved by the EU and individual Eastern countries at the beginning of the 1990s. The EU granted GSP status first to Hungary and Poland (1990), then to Bulgaria and former Czechoslovakia (1991), and subsequently to Estonia, Latvia and Lithuania (1992). All these reforms culminated with the accession of all the Border countries to the European Union (Croatia is expected to do it very soon).

\footnotetext{
1 The simulations run under this alternative specification are available upon request.

2 Bosnia, Montenegro and Serbia are not considered because not all data were available since 1990.
} 


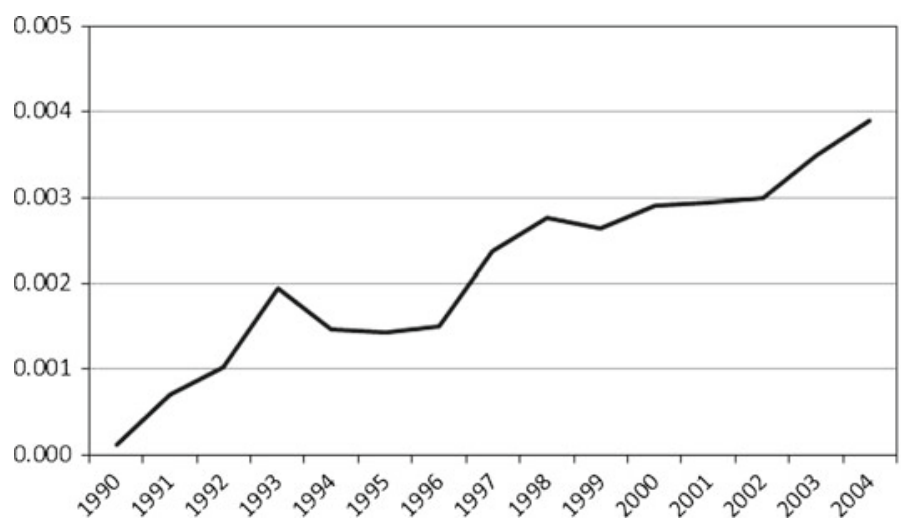

Fig. 4 Border-West Industrial Trade freeness (calculated as a yearly median for all the possible/available country pairwise and 38 ISIC Rev. 2 at the combined 3-digit industry classification level)

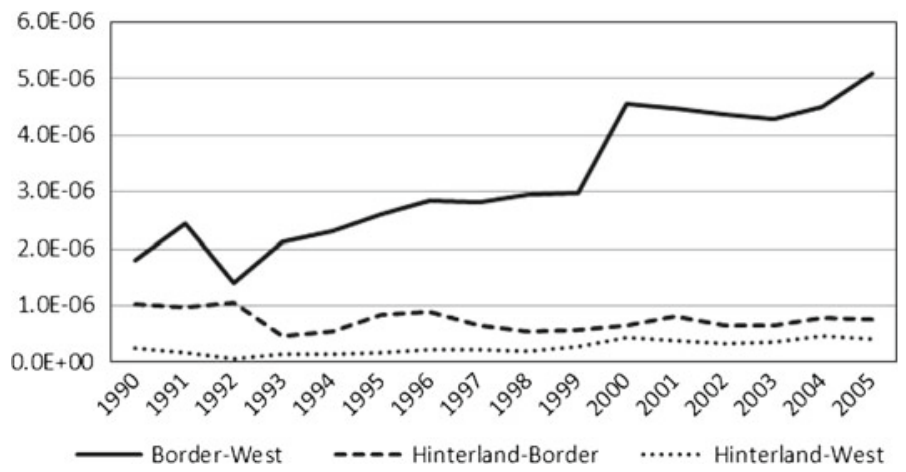

Fig. 5 Aggregated Trade freeness

In Fig. 4, we display the evolution of the three region-pairwise macroeconomic trade freeness (using data from IMF Bilateral Trade Statistics). Moreover, in Fig. 5, we also display the West-Border evolution of the medians of the trade freeness across industrial sectors (using data from Nicita and Olarreaga 2007). The concept of trade freeness, used by Head and Mayer (2004), is an inverse measure of the magnitude of the trade costs between two particular locations. It is computed in the following way:

$$
\emptyset_{i j}=\left(\frac{m_{i j} m_{j i}}{m_{i i} m_{j j}}\right)^{1 / 2}
$$

where $\emptyset_{i j}$ denotes the trade freeness between locations $i$ and $j ; m_{i j}$ stands for country $i$ 's imports of country $j$ 's manufacturing goods; and $m_{i i}$ represents country $i$ 's shipments to itself, computed as the difference between the value of the gross output in the producing country minus the aggregate value of its exports.

Figures 4 and 5 show how remarkable was the rise of the aggregate and industrylevel West-Border's trade freeness during the period under consideration. On the contrary, the aggregate trade freeness remained quite stable between West-Hinterland and 
Border-Hinterland. Unfortunately, the inexistence of industry-level data on gross output and bilateral trade for the Border and Hinterland countries prevented us from calculating the evolution of the industry-level West-Hinterland and Border-Hinterland's trade freeness.

\subsubsection{Limited migration}

According to Kaczmarczyk and Okolski (2005), during the communist era, migration in Eastern Europe was negligible, both within and between countries. Rural-to-urban mobility was also greatly delayed and generally low. Moreover, in contrast to Western European nations, in many Eastern countries, the process of industrialization took place in the absence of massive urbanization.

It was during the 1990s that substantial policy reforms were enacted to liberalize labor flows across Eastern European countries. For example, in 1993, the Czech Republic established a liberal migration policy which turned the country into the home to tens of thousands of migrants from Europe and Asia (Drbohlav 2005). In 1993, Russia abolished the internal passport and allowed for freedom of movement (Heleniak 2002). This also resulted in many migrants coming from other Hinterland countries.

However, the magnitude of the Hinterland-Border permanent migratory movements was relatively insignificant. According to Mansoor and Quillin (2006), "there are minimal flows from the CIS [Hinterland] states into the [Border]", which amount approximately to $5 \%$ of the CIS countries total emigration flow. Such flow from the Hinterland to the Border could be quantified for the year 2003 in about 300 thousand people, out of 6 million people who permanently emigrated from their Hinterland country in that particular year.

The migration from Border to Western European counties between 1990 and 2000 faced the existence of many restrictions, and the migration Hinterland to West was inexistent. In this context, a notable exception was the migration of Eastern European ethnic Germans toward their homeland. Hence, the stock of Border's immigrants in the Western Europe only rose from 758,193 to 965,724 in the period 1990-2000 (see Pytlikova 2006). However, from the turn of the century, the Border-West migration gained significance. According to Boeri and Brücker (2005), the stock of immigrants increased in 1.1 million between 1990 and 2005. Thus, in the five-year period 20002005 , the stock of immigrants has roughly increased 4.3 times more than it did in the previous decade, though the 1.1 million represents only $1 \%$ of Border's population in 1990.

\section{Main stylized facts}

The three stylized facts we aim to account for in our theoretical model are as follows:

\subsection{U-shaped pattern of relative income per capita between East and West}

In Fig. 1, we see that the relative income per capita between East and West diverges until 1999 and starts to converge thereafter. 


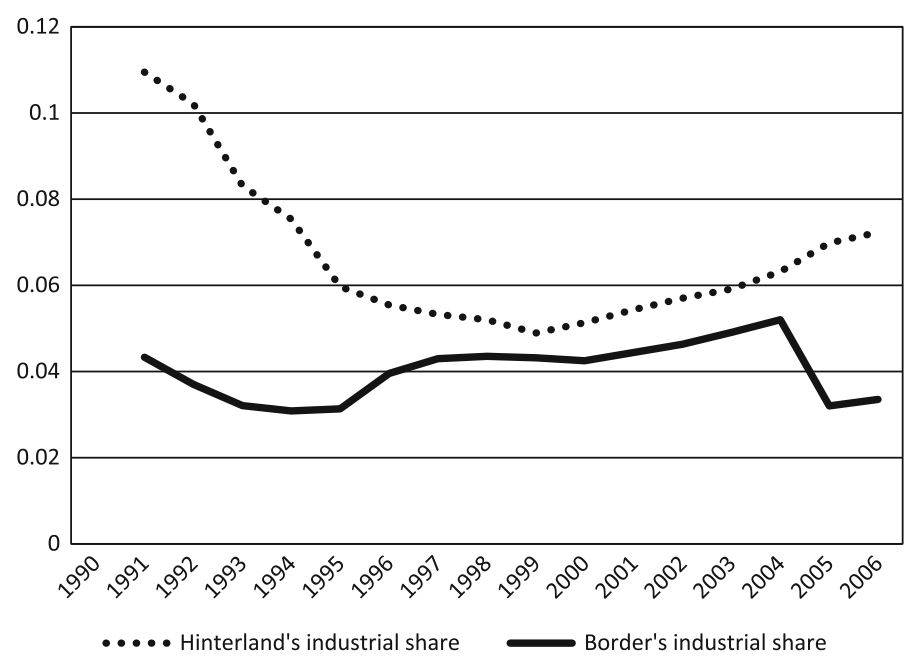

Fig. 6 Border and Hinterland shares of the European industrial output

4.2 U-shaped pattern of relative income per capita within East (Hinterland relative to Border)

This can be seen in Fig. 1, where the turning point is again around 1999.

\subsection{U-shaped pattern of industrialization between East and West and between Hinterland and Border}

Figure 6 shows the industrial output's share of both Border and Hinterland as a fraction of the aggregate European industrial output. It is apparent that the Border keeps a roughly stable share, whereas the Hinterland's share initially decays sharply but firmly recovers later. We recognize that it is a frequent suspicion that the industrial and GDP revival of the Hinterland may be linked to the "petro-boom" experienced by resourcerich countries like Russia. However, we show in Figs. 7 and 8 that the U-shaped patterns are robust to the exclusion of the Russian Federation from the Hinterland.

\section{The model}

\subsection{Overview}

In order to make the reading easier and given that our model is an application of Puga (1999), we have decided to move its lengthy mathematical description to the "Appendix". This model considers a framework with two blocks (West and East) and three regions: West $(W)$, and Border $(B)$ and Hinterland $(H)$ in East. There are two sectors, agriculture and industry; two factors of production, labor and land; and both blocks have identical technologies. East is a larger block in terms of land area 


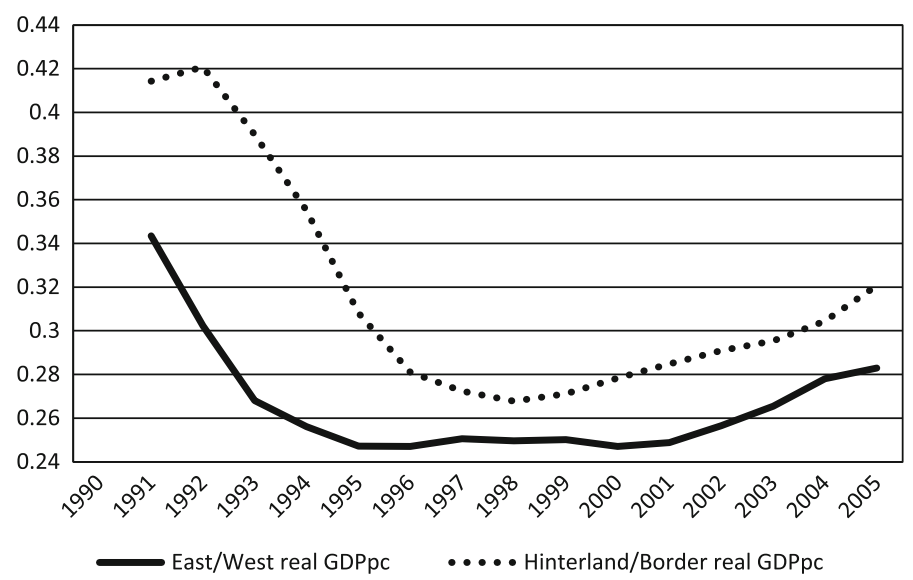

Fig. 7 East/West and Hinterland/Border Real GDP per capita, excluding Russia

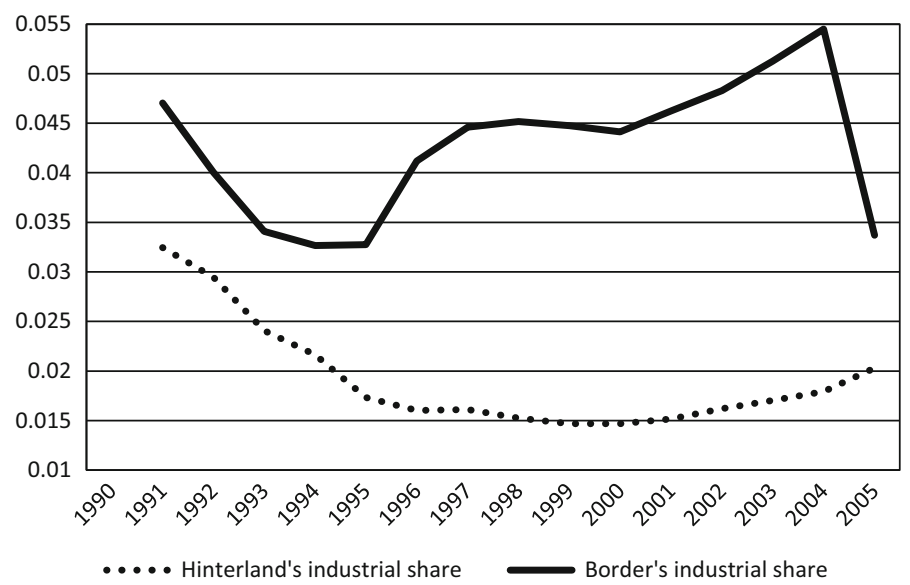

Fig. 8 Border and Hinterland shares of the European industrial output, excluding Russia

and population, though the Western market is better integrated due to the absence of internal trade costs.

Each region $i$ endowment's shares $L_{i}$ and $K_{i}$ (for population and land area, respectively) of the three regions' aggregate are detailed as follows: the shares for the year 1990 are used, $L_{i 90}$ and $K_{i 90},{ }^{3}$ except for labor in West and Border, which are allowed to change according to the migration flows. For the latter case, it is assumed that individuals get a disutility from emigration, and hence, they do not emigrate unless such disutility is offset by real-wage differentials (see the "Appendix" for more details).

Trade in industrial goods is subject to different transport costs for each region pairwise (details in the next section). The agricultural good is produced under perfect

\footnotetext{
3 These shares are obtained from the World Development Indicators and remained very stable along the entire time period.
} 
competition, using land and labor as inputs. Since the supply of land is fixed, the agricultural sector faces decreasing returns to labor. This entails that agriculture endogenously takes place in all locations. The monopolistically competitive industrial sector uses labor and intermediate goods, giving rise to forward and backward linkages. Our model is very much similar to Puga (1999), though it exhibits two basic differences. That is, the introduction of transport costs between Border and Hinterland, which prevents the full convergence of Eastern and Western welfare levels, even under perfect trade openness between East and West. The second difference is the introduction of migration disutility.

\subsection{Numerical simulations}

\subsubsection{Parameterization}

The goal of this section is to carry out an experiment that looks at the effect that a gradual decrease in mainly West-Border trade costs (due to trade and migration liberalization) has on GDP per capita and industrial convergence.

The values for our model's parameters are mainly taken from Bosker et al. (2010), who empirically estimated the parameters in Puga (1999)'s model. These authors used a sample of 194 EU-15 NUTS-II regions over the period 1992-2000 and then applied such estimation to simulate the impact (on the West) of the ongoing integration with the Border countries. As it was stated earlier, our aim is to replicate the stylized facts (1), (2) and (3) by focusing on the pure effects of geography and trade liberalization without resorting to taste or technological differences between the East and the West. Therefore, the structural parameter estimates, described in the "Appendix", are as follows:

\begin{tabular}{lll}
\hline$\sigma$ & Elasticity of substitution between manufacturing varieties & 7.122 \\
$\gamma$ & Share of consumers' income spent on manufactures & $0.7^{\mathrm{a}}$ \\
$\mu$ & Share of firms' revenue spent on intermediates & 0.284 \\
$\emptyset$ & Labor elasticity in the agricultural production function & 0.234 \\
\hline
\end{tabular}

a Bosker et al. (2010) uses $\gamma=0.994$, which reflects the share of income spent on anything but agricultural products for the EU-15. At the same time, they consider the possibility of using $\gamma=0.335$, which is the share of industrial goods on aggregate consumption. We have considered more appropriate to report results for a $\gamma$ in between these two values, but our results are robust to a value of $\gamma=0.994$

Trade in industrial goods is subject to transport costs, represented by the parameters $\emptyset_{W-B}, \emptyset_{B-H}$ and $\emptyset_{W-H}$ with $\emptyset_{W-H}=\emptyset_{W-B} \times \emptyset_{B-H}$ and where $\emptyset=0(\emptyset=1)$ can be translated as to an infinite (zero) trade cost. For our simulations, we assume that $\emptyset_{B-H}$ remains constant throughout the whole period at 0.01 while $\emptyset_{W-B}$ linearly increases from 0 to 1 .

In our simulations, we do not intend to capture the whole set of stable (and unstable) equilibria at any level of the trade costs. We just obtain an initial West-East autarky equilibrium, $\emptyset_{W-B}=\emptyset_{W-H}=0$, and then, as the trade costs fall, we increase 


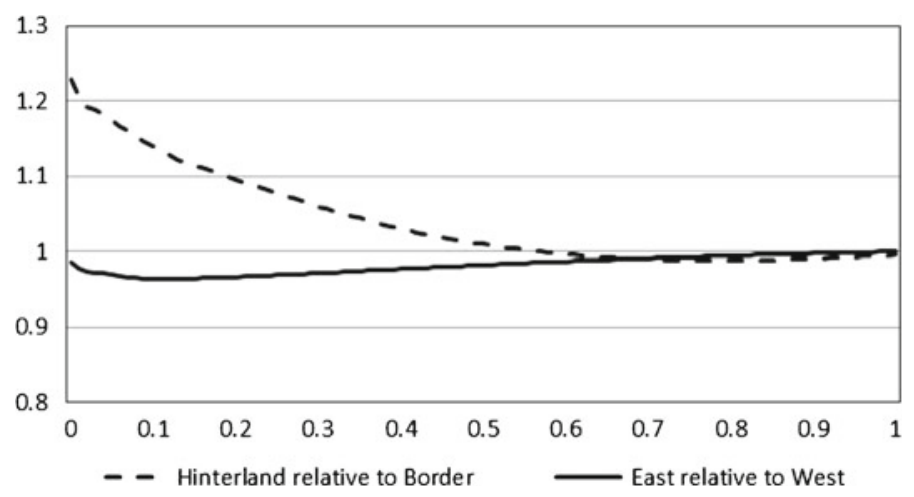

Fig. 9 Simulated real wages_-East relative to West and Hinterland relative to Border

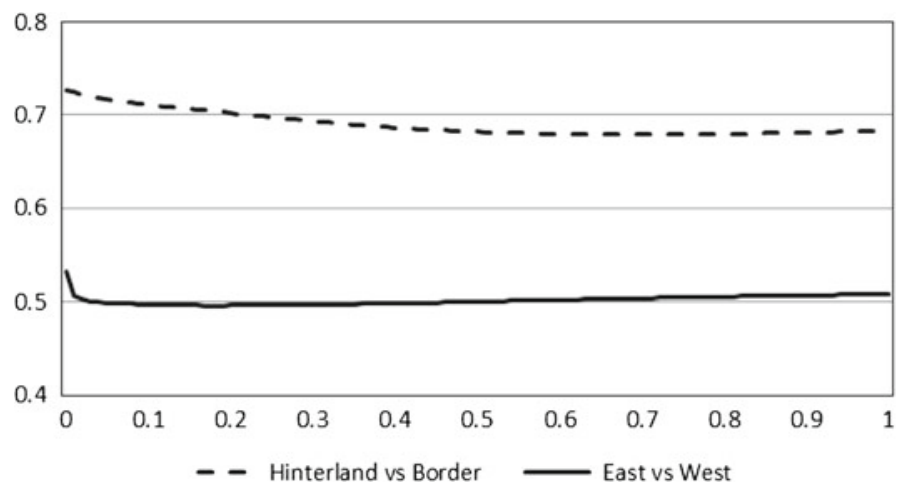

Fig. 10 Simulated industrial output ratios_-East relative to West and Hinterland relative to Border

(decrease) the local mass of manufacturing varieties in those locations where profits are positive (negative) until the zero-profit condition is satisfied. Thus, a sequence of equilibria is obtained.

\subsubsection{Trade liberalization}

The results for our scenario can be seen in Figs. 9 and 10, where the horizontal axis shows the (increasing) degree of West-Border trade freeness. Initially, Eastern and Western markets are completely isolated from each other. As $\emptyset_{W-B}$ and at a lesser extend $\emptyset_{W-H}$ start to rise, there is the appearance of tougher competition for both Eastern locations (especially for the Border), whereas the Western market is hardly affected by the scant competitors in the Border and the more distant firms in the Hinterland. This leads to a process of East-West divergence. Nevertheless, openness to the Western market implies not only tougher competition, but also higher exports and cheaper imports of intermediates in the East, especially in the Border. The proximity to a large market is crucial for the Border to absorb a portion of Hinterland's manufacturing share, leading to a process of within-East divergence. 


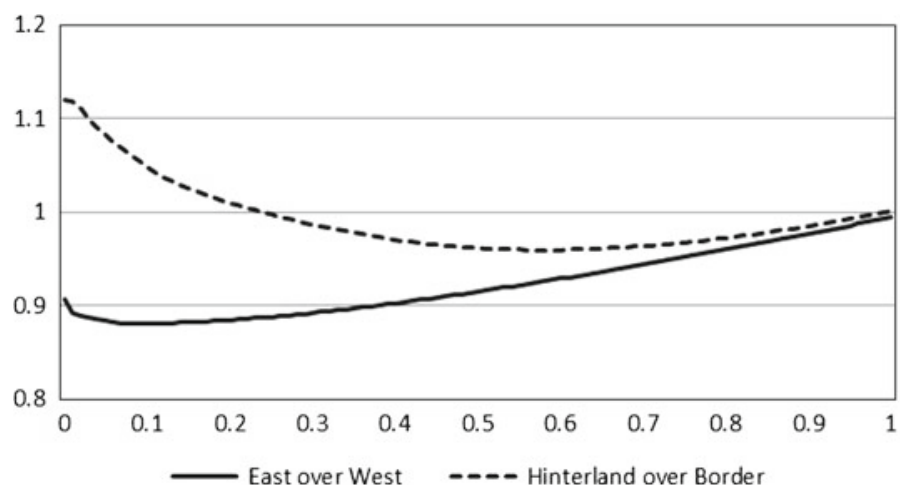

Fig. 11 Simulated real wages - East relative to West and Hinterland relative to Border (excluding Russia)

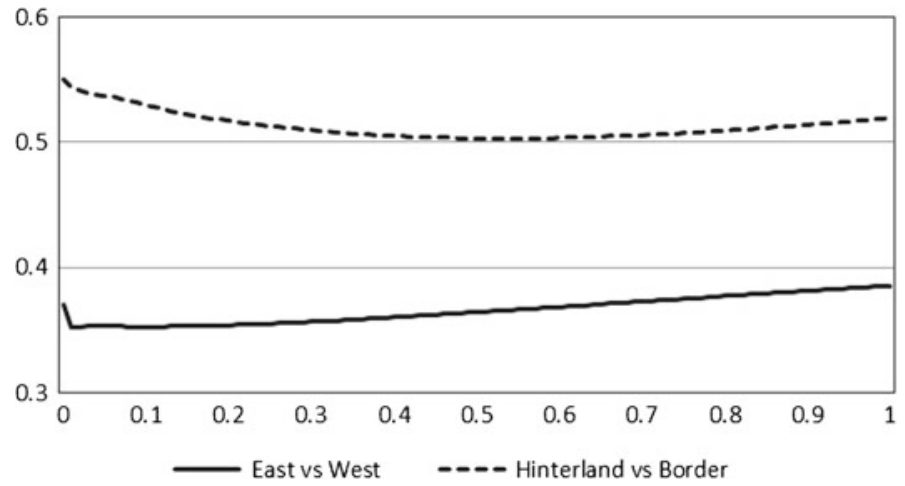

Fig. 12 Simulated industrial output ratios-East relative to West and Hinterland relative to Border (excluding Russia)

Once trade openness between our three locations starts to be sufficiently high, being closer to large markets - with abundant purchasing power-ceases to be the firms' main priority. Simultaneously, the previous Eastern deindustrialization creates a reservoir of cheap labor in the primary sector of the East, especially in the Hinterland, whereas the Western labor costs have been growing higher and higher.

Lower nominal wages in the East, together with the possibility to import Western intermediates more cheaply, end up precipitating the consecutive reindustrialization of both Eastern locations: starting with the Border and followed by Hinterland, once the wages in the former surge. Remoteness was Hinterland's initial disadvantage but once relative wages become lower there and land rents more abundant, industrial profitability returns. As a robustness check, in Figs. 11 and 12, we show the simulation results with Russia excluded, which show no significant difference to the previous ones.

\section{Microeconomic evidence at the industry level}

This section brings industry-level evidence to give additional support to our hypothesis that NEG forces were at work during the aforementioned regional convergence pattern. 


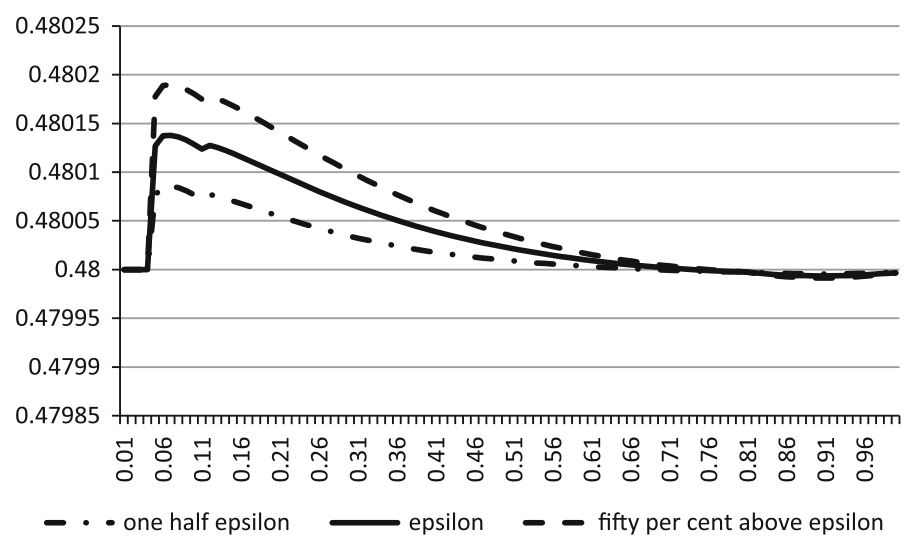

Fig. 13 Simulated values of the population in the West when Russia is included in the Hinterland. Curves are drawn with the calibrated value of $\varepsilon$, with one half of such value and $50 \%$ above such value

The argument is that the industries exhibiting higher scale economies and/or valueto-weight ratios are more susceptible of facing a spatial concentration of their output, hence more affected by the centripetal and centrifugal forces characteristic of the NEG. Therefore and as suggested by Forslid et al. (2002), for intermediate values of the sectorial trade freeness and if such forces were the predominant ones, these sectors should tend to concentrate in the larger market.

Our task faced the challenge put by the large scarcity of data for both industry-level output and bilateral trade for Border and their practically inexistence for Hinterland. However, we have managed to single out a few country-pairwise industry-level outputconcentration ratios for a selection of relevant West-Border pair of countries and graph them against the industry-level values of trade freeness.

Figure 14 shows that sectors with important scale economies and/or high value-toweight's ratios (first three columns) display an inverted U-shaped pattern (or something close to it) of their output concentration in the West as the trade freeness increases. In contrast, sectors where scale economies are less relevant and value-to-weight ratios are lower (last three columns) follow a monotonic concentration pattern. The latter is more consistent with theories of comparative advantage. Our judgments were based on the sectorial scale economies' ranking taken from Pratten (1988) as well as the value-to-weight ratio from the US-Canada Trade Statistics-North American Transborder Freight data (NATBF). In particular, the first three columns in Fig. 14 collect sectors that are either within the first 10 in Pratten's scale economy ranking and/or within the first 20 in terms of the value-to-weight ratio. The sectors grouped in the last three columns do not satisfy any of the two previous requirements.

The mentioned stylized facts seem to be exclusive to the NEG approach and less so to the conventional technological-obsolescence approach. The latter could explain a macroeconomic U-shape pattern and could even possibly predict the existence of a U-shape (monotonic) pattern in relative more (less) obsolete sectors. However, it would not predict the above stylized facts, except in the case that the sectors with higher economies of scale and/or higher value-to-weight ratios were also the ones which have 

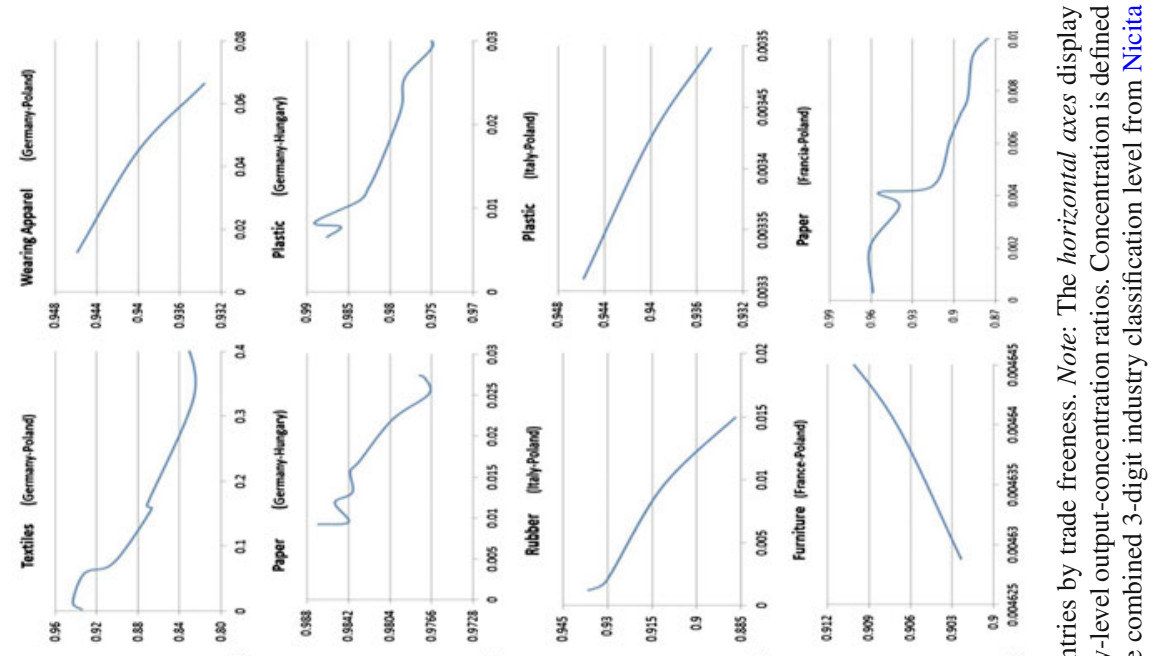

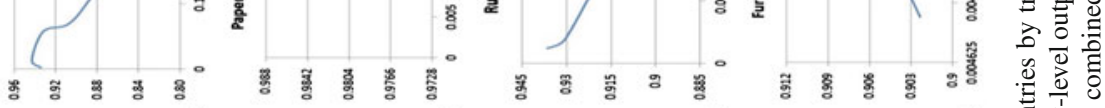
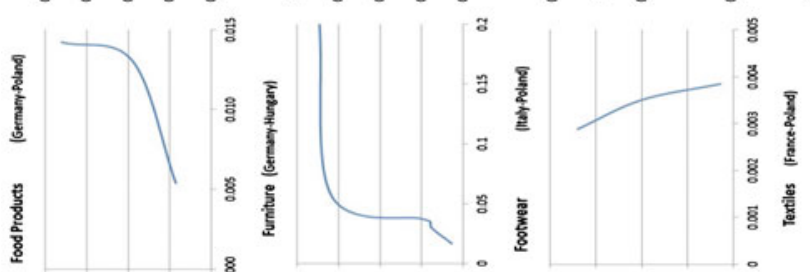

$\sum$.

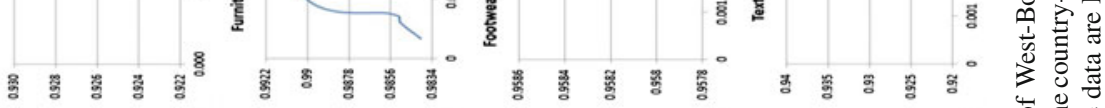
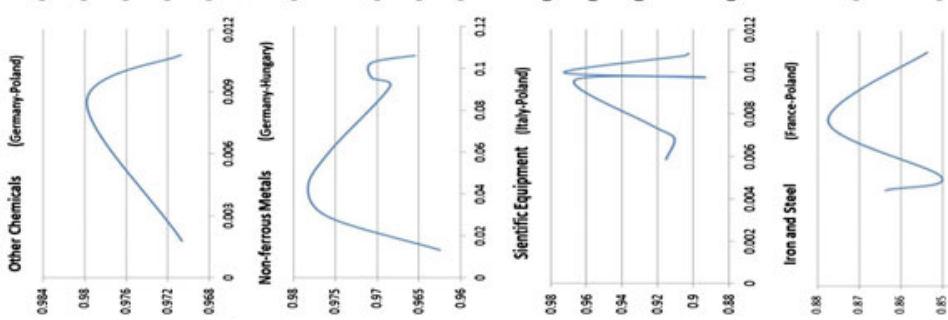

岁焉
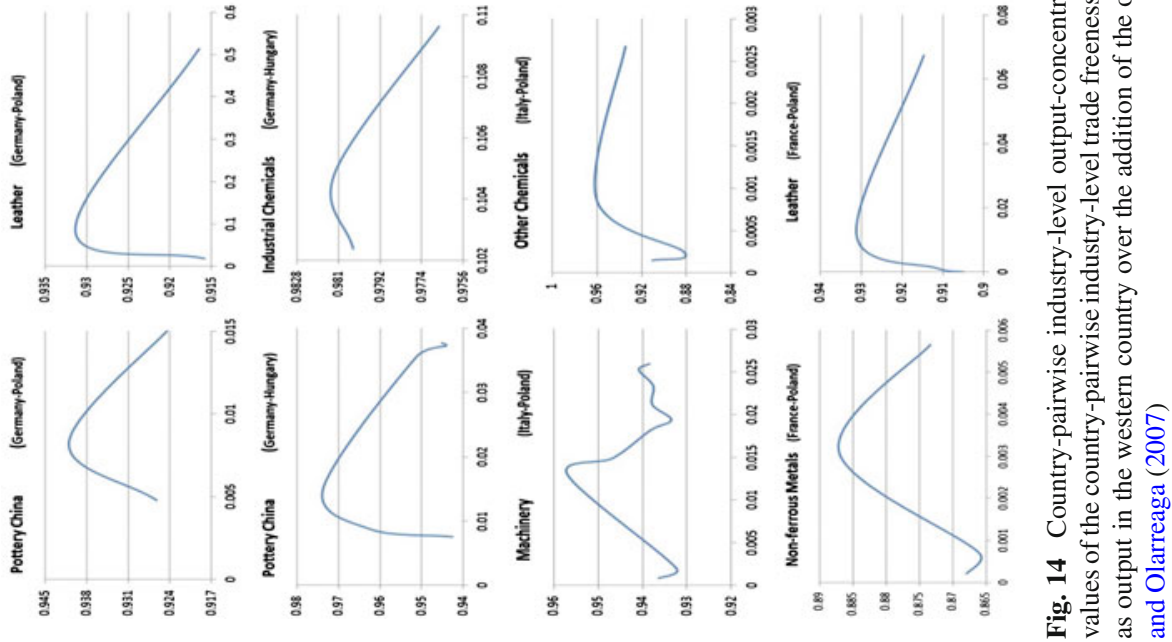
suffered a higher technological obsolescence. However, it seems difficult to think that, for instance, Leather and Pottery China have suffered a high obsolescence. Similarly, the ex-communist countries were quite advanced in the production of Non-Ferrous Metals and even Chemicals and so they do not seem to represent their relatively more obsolete sectors.

\section{Conclusions}

In this paper, we have examined some mechanisms - exclusively related to economic geography and trade openness - as possible ingredients to account for the relative income profile (and industrialization) of transition countries along the period 19902005. We have deliberately disregarded any consideration of technological differences or unrelated public-policy factors, and hence, our explanations can be considered as complementary to those presented in the literature.

Initially, higher trade openness generates a deterioration of the industrial capacity in the East in favor of the West, due to the higher integration of the market in the latter location. Something similar happens between Hinterland and Border, where foreign inputs are much cheaper. As a result, the early stages of trade liberalization are characterized by both East-West and Border-Hinterland divergence. Later, lower marginal costs channel a recovered manufacturing profitability toward the East, first to the Border and later to the Hinterland, which finally gets reindustrialized under our parameterization. This fact also drives the revival of the East relative to the West.

\section{Appendix}

Our model is a slight extension of Puga (1999)'s model. $K_{i}$ and $L_{i}$ are the stocks of land and labor in each block $i$, normalized as shares of the total stocks in the blocks. Moreover, the labor shares of Border and West are adjusted by the evolution of migration.

\subsection{Demand}

There is a food sector $(F)$, the numeraire and an industrial sector. Consumers have Cobb-Douglas preferences over the primary good and a CES composite of manufacturing varieties (or varieties for short) with industrial expenditure share, $0<\gamma<1$. Maximizing the CES sub-utility function subject to the income constraint yields the consumer demand for each variety $h(8.1)$, where $\mathrm{Y}$ is the consumer's income, $q$ is the manufactures' price index, and $\sigma$ and $p(h)$ are the varieties' elasticity of substitution and c.i.f. price, respectively.

$$
c(h)=p(h)^{-\sigma} q^{\sigma-1} \gamma Y ; q=\left(\int_{0}^{n} p(h)^{1-\sigma} \mathrm{d} h\right)^{1 /(1-\sigma)}
$$


Firms also use varieties as intermediates for which also have an elasticity of substitution $\sigma$. The local demand for a variety depends on the spending by both global consumers and local firms. The aggregate spending from location $i$ on any variety is $e_{i}=\gamma Y_{i}+\mu n_{i} p_{i} x_{i}$, where $n_{i}\left(x_{i}\right)$ is the mass of produced varieties (the equilibrium output of any variety) in region $i$. The first term is the share of aggregate consumers' income spent on manufactures, and the second is the expenditure on intermediates.

\subsection{Manufacturing supply}

The manufacturing sector is monopolistically competitive. The production input in manufacturing is a Cobb-Douglas composite of labor (with a wage rate of $w_{i}$ ) and intermediates. Total cost in region $i$ is as follows:

$$
C\left(x_{i}\right)=\left(q_{i}^{\mu} w_{i}^{1-\mu}\right)\left(\alpha+\beta x_{i}\right)
$$

where $\alpha$ and $\beta$ are the fixed-cost and marginal-input requirements for each variety. Profit maximization results in a constant mark-up over marginal costs, as shown in $(8.3):^{4}$

$$
p_{i}=\left(q_{i}^{\mu} w_{i}^{1-\mu}\right)
$$

Finally, using the zero-profit condition and the mark-up pricing rule (8.3), we get that the break-even supply of any variety is $x_{i}=1$.

\subsection{Supply of food}

Consumers' income comes from two sources, local workers' wages and/or agricultural rents. Agriculture produces a homogeneous good under constant returns to scale, perfect competition and no transport cost across locations. Its production in region $i$ depends on the available local land $\left(K_{i}\right)$ and labor $\left(L_{F, i}\right)$ such that

$$
F=F\left(L_{F, i}\right)=\left(L_{F, i}\right)^{\theta} K_{i}^{1-\theta}
$$

By applying rent maximization, the aggregate agricultural rents in location $i$ are $R_{i}=(1-\theta) K_{i}\left(\frac{\theta}{w_{i}}\right)^{\frac{\theta}{1-\theta}}$, which added to the labor income gives region's $i$ aggregate nominal income

$$
Y_{i}=w_{i} L_{i}+R_{i}
$$

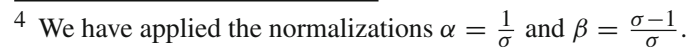


8.4 Equilibrium with transport costs

As a result of (8.1) and the conditions of the demand for manufacturing varieties, the total demand faced by a firm $h$ located in region $i$ is

$$
x_{i}(h)=\sum_{j \in\{B, H, W\}}\left(p_{i}(h)\right)^{-\sigma} e_{j} q_{j}^{\sigma-1} T_{i j}^{1-\sigma}
$$

where $T_{i j}$ is the trade cost from region $i$ to $j$, and $e_{j}$ is the aggregate level of expenditure on manufactures in region $j$. Then, from expressions (8.2), (8.3) and the normalizations in footnote (4), the profits of any manufacturing firm in region $i$ are

$$
\pi_{i}=\frac{p_{i}}{\sigma}\left(x_{i}-1\right)
$$

The labor-market-clearing condition for any region $i$ results in the local labor supply being (from (8.2) and the profit-maximization conditions in the agricultural sector)

$$
L_{i}=(1-\mu) \frac{C\left(x_{i}(h)\right)}{w_{i}} n_{i}+K_{i}\left(\frac{\theta}{w_{i}}\right)^{\frac{1}{1-\theta}}
$$

where the first (second) term of (8.8) is the manufacturing (agricultural) labor demand.

\subsection{Labor mobility}

Labor migration (and re-migration) takes place only between Border and West. Individuals have an idiosyncratic home-biased preference, represented by a parameter $\theta$, which implies they get a disutility from emigration. They do not emigrate unless such disutility is offset by real-wage differentials. For instance, a Border's inhabitant would migrate to the West if and only if $\frac{w_{W}}{q_{W}^{\gamma}}>\theta \frac{w_{B}}{q_{B}^{\gamma}}$, where $\frac{w_{i}}{q_{i}^{\gamma}}$ is region's $i$ real wage. As in Faini (1996), $\theta$ is distributed (across a region's population) according to a Pareto density function, $f(\theta)=\frac{\varepsilon}{\theta^{\varepsilon+1}}$ with $\theta \in(1, \infty)$ and . Thus, the fraction of the original population from the Border that does not migrate is

$$
\Psi_{B}=\int_{\frac{w_{W}}{\frac{q_{W}^{\gamma}}{\frac{w_{B}}{q_{B}^{\gamma}}}}}^{\infty} f(\theta) \mathrm{d} \theta=\min \left\{\left[\frac{\frac{w_{B}}{q_{B}^{\gamma}}}{\frac{w_{W}}{q_{W}^{\gamma}}}\right]^{W}, 1\right\}
$$

and so the percentage of the Border's population that migrates, $1-\Psi_{B}$, increases with the wage differential. $\varepsilon$ can be considered as an indicator of the degree of labor mobility. 
Similarly, since we allow in principle for labor mobility in both directions, the fraction of the original population from the West that remains there is

$$
\Psi_{W}=\int_{\frac{w_{B}}{\frac{w_{B}}{w_{W}}}}^{\infty} f(\theta) \mathrm{d} \theta=\min \left\{\left[\frac{\frac{w_{W}}{q_{W}^{\gamma}}}{\frac{w_{B}}{q_{B}^{\gamma}}}\right]^{\epsilon}, 1\right\}
$$

We have incorporated migration flows to our simulations, after calibrating one parameter $(\varepsilon)$ measuring how big is the propensity to migrate of the population from the Border and the West. Such calibration has followed Faini (1996)'s functional form.

People from the Border and the West will only start migrating when the relative wage of their homeland is the lower of the two. Therefore, our chosen equations describing labor mobility are as follows:

$$
L_{w}=0.48 \Psi_{W}+0.14\left(1-\Psi_{B}\right) ; L_{B}=0.62-L_{w}
$$

where 0.48 and 0.14 are the population shares of the West and the Border, respectively, in 1990. As commented in Sect. 3.2., Border-West migration only started in earnest by the turn of the century. Therefore, our simulations reflect the possibility of migration for values of Border-West trade freeness equal or higher than $\emptyset_{W-B}=0.04$. Our qualitative results are robust to the introduction of very different choices for that delay.

Given that $1 \%$ of the Border population migrated to EU15 between 1990 and 2005, and prior to 1990, we can assume that Border-West migration was not allowed, and in our model, these facts imply that

$$
0.01=1-\Psi_{2005}
$$

Let us denote by $r$ to the ratio of Border-West GDP per capita in 2005. Then,

$$
\varepsilon=\frac{\ln (0.99)}{\ln (r)} \approx 0.00672
$$

The simulated pattern of migration and remigration is described in Fig. 13, for the case in which Russia is not omitted from the Hinterland. ${ }^{5}$ There we can observe how the West absorbs initially a small share of the Border population, which will be gradually re-migrating later toward the homeland. As shown in Fig. 13, our simulated (qualitative) results in terms of the patterns of development are robust to any reasonable variation in the value of $\varepsilon$.

\footnotetext{
5 The graph for the case in which Russia is omitted is basically isomorphic, though the initial population shares in 1990 are different. That figure is also available upon request.
} 
Acknowledgments We are greatly indebted to Klaus Desmet for his invaluable and patient guidance. Moreover, Susana Iranzo suggested the title and provided us with especially useful comments. We also benefited from the ideas and remarks of Ramiro de Elejalde, Matthias Dahm, Juan Dolado, Gino Gancia, Belen Jerez, Seongman Moon, Volcker Nitsch, Diego Puga, Georges Siotis and Andreas Waldkirch. A grateful mention is also due to the editor, Janet E. Kohlhase and two anonymous referees. Additional recognition is deserved by Abdul Rashid Rahim Dad and Abdul Aziz Osman Abahinde for their excellent research assistance. Finally, this work aims to modestly contribute to the memory of the deceased Prof. Howard Petith. The usual disclaimer applies.

\section{References}

Ago T, Isono I, Tabuchi T (2006) Locational disadvantage of the hub. Ann Reg Sci 40(4):819-848

Alonso-Villar O (1999) Spatial distribution of production and international trade: a note. Reg Sci Urban Econ 29(3):371-380

Behrens K, Gaigne C, Ottaviano G, Thisse J (2006) Is remoteness a locational disadvantage? J Econ Geogr 6(3):347-368

Blanchard O (1996) Theoretical aspects of transition. Am Econ Rev 86(2):117-122

Blanchard O, Kremer M (1997) Disorganization. Q J Econ 112(4):1091-1126

Boeri T, Brücker H (2005) Why are Europeans so tough on migrants? Econ Policy 20(44):629-703

Boldrin M, Canova F (2003) Regional policy and the EU enlargement. In: Funck B, Pizzati L (eds) European integration, regional policy, and growth. The International Bank for Reconstruction and Development/The World Bank. Washington, DC

Bosker M (2009) The spatial evolution of regional GDP disparities in the 'old' and the 'new' Europe. Pap Reg Sci 88(1):3-27

Bosker M, Brakman S, Garretsen H, Schramm M (2010) Adding geography to the new economic geography: bridging the gap between theory and empirics. J Econ Geogr 10(6):793-823

Brulhart M, Koenig-Soubeyran P (2006) New economic geography meets Comecon. Regional wages and industry location in central Europe. Econ Transit 14(2):245-267

Brulhart M, Crozet M, Koenig-Soubeyran P (2004) Enlargement and the EU periphery: the impact of changing market potential. World Econ 27(6):853-875

Campos N, Coricelli F (September 2002) Growth in transition: what we know, what we don't and what we should. J Econ Lit, XL, pp 793-836

Christoffersen P, Doyle P (1998) From inflation to growth: eight years of transition. IMF working paper

Cociuba S (2006) A theory of transition to a better technology. University of Minnesota and Federal Reserve Bank of Minneapolis

Crozet M, Koenig-Soubeyran P (2004) EU enlargement and the internal geography of countries. J Comp Econ 32:265-279

De Melo M, Denizer C, Gelb A, Tenev S (2001) Circumstance and choice: the role of initial conditions and policies in transition economies. World Bank Econ Rev 15(1):1-31

Drbohlav D (2005) The Czech Republic: from liberal policy to EU membership. Migration Policy Institute, Washington

Faini R (1996) Increasing returns, migrations and convergence. J Dev Econ 49:121-136

Forslid R, Haaland J, Maestad O (2002) Integration and transition: scenarios for location of production and trade in Europe. Econ Transit 10(1):93-117

Head K, Mayer T (2004) The empirics of agglomeration and trade, Handbook of Regional and Urban Economics, In: Henderson JV, Thisse JF (eds) Handbook of Regional and Urban Economics, 1st edn, vol 4, chap 59, Elsevier, pp 2609-2669

Heleniak T (2002) Migration dilemmas haunt post-Soviet Russia. Migration Policy Institute, Washington

Iranzo S, Peri G (2009) Migration and trade in a world of technological differences: theory with an application to Eastern-Western European integration. J Int Econ 79(1):1-19

Kaczmarczyk P, Okolski M (2005) International migration in Central and Eastern Europe-current and future trends. UN Expert Meeting on International Migration and Development

Keller W (1997) From socialist showcase to Mezzogiorno? Lessons on the role of technical change from East-Germany's post-world war II growth performance, NBER, working paper 6079

Krugman P (1991) Increasing returns and economic geography. J Political Econ 99(3):483-499 
Krugman P, Livas-Elizondo R (1996) Trade policy and the third world metropolis. J Dev Econ 49(1): $137-150$

Krugman P, Venables A (1995) Globalization and the inequality of Nations. Q J Econ 110(4):857-880

Mansoor A, Quillin B (2006) Migration and remittances. Eastern Europe and the former Soviet Union. The World Bank, Washington

Melchior A (2008) East-West integration and the economic geography of Europe. NUPI working paper

Monfort P, Nicolini R (2000) Regional convergence and international integration. J Urban Econ 48(2): 286-306

Nicita A, Olarreaga M (2007) Trade, production and protection 1976-2004. World Bank Econ Rev 21(1):165-171

Pratten C (1988) A survey of the economies of scale. In: Commission of the European Communities. Research on the cost of Non-Europe, vol 2, Studies on the Economics of Integration, Luxembourg

Puga D (1999) The rise and fall of regional inequalities. Eur Econ Rev 43(2):303-334

Pytlikova M (2006) Migration flows from the perspective of sending and receiving countries. PhD Thesis. Department of Economics. Aarhus School of Business

Tondl G, Vuksic G (2003) What makes regions in Eastern Europe catching up? The role of foreign investment, human resources and geography. IEF working paper, No 51

Venables A (2000) Cities and trade: external trade and internal geography in developing countries. In: Yusuf S, Evenett S, Wu W (eds) Local dynamics in an era of globalization: 21st century catalysts for developments. OUP and World Bank, Washington 